УДК 811.112 .2

\title{
Н.В. Кожанова
}

\section{СОВРЕМЕННЫЕ НЕМЕЦКИЕ ОБЪЯВЛЕНИЯ О ВАКАНСИИ КАК ПОЛИКОДОВЫЙ TEKCT}

В статье рассматриваются особенности современного немецкого объявления о вакансии в контексте оппозиции монокодовых и поликодовых текстов. Основное внимание в работе акцентируется на принадлежности данных текстов к двум семиотическим системам (немецкого и английского языков), которые могут рассматриваться как основные вербальные составляющие объявления о вакансии, соединяющиеся в единое целое общей целеустановкой, характерной для данного типа текста. Речь идет об англоязычных включениях в текстах немецких объявлений о вакансии, в которых находит свою объективацию этноспецифическая информация, относящаяся к англоязычной картине мира. В статье отмечается, что вопрос о соотношении английской и немецкой языковых картин мира в сознании носителя немецкой культуры остается дискуссионным. Представленный материал позволяет сделать вывод, что увеличение числа подобных объявлений свидетельствует о значительных изменениях на всех уровнях коммуникативной практики: на семиотическом, на когнитивном, на прагматическом.

Ключевые слова: наименования лиц по профессии, поликодовый текст, креолизованный текст, дикодовый текст, функция создания имиджа.

DOI: $10.35634 / 2412-9534-2020-30-2-258-263$

Расширение предметной области лингвистики, обусловленное становлением новой антропоцентрической парадигмы научного знания, заставило по-новому взглянуть на многие традиционные для лингвистики объекты исследования, к которым, без сомнения, относится текст. Рассмотрение понятия текста в контексте языковой личности, способной выступать как в качестве автора, так и адресата текста, стимулировало исследования взаимосвязей и взаимозависимостей между элементами текста и феноменами культуры, которая предстает в лингвистических исследованиях как сложная многоуровневая семиотическая система, поэтому в центре исследовательского внимания оказываются тексты с неоднородной семиотической структурой, за которыми закрепляется термин «поликодовые тексты».

Впервые оппозиция моно- и поликодовых текстов выделена в 1974 г. Г.В. Ейгером и Л. Юхтом. «К поликодовым текстам в широком семиотическом смысле должны быть отнесены случаи сочетания естественного языкового кода с кодом какой-либо иной семиотической системы» [6, с. 107]. Термин «поликодовый текст» используется Л.М. Большияновой [3, с. 51]. Автор исследовала «лингвовизуальный комплекс» - газетный текст, сопровождаемый фотоизображением, как разновидность поликодовых текстов. А.Г. Сонин называет поликодовыми «тексты, построенные на соединении в едином графическом пространстве семиотически гетерогенных составляющих - вербального текста в устной или письменной форме, изображения, а также знаков иной природы» [7, с. 117].

Поликодовые тексты часто называют «креолизованными текстами», так как они организованы комбинацией естественного языка с элементами других знаковых систем или упорядоченных множеств [2, с. 20]. Следует подчеркнуть, что явление креолизации является неотъемлемым свойством коммуникации и человеческой культуры в целом. Наш мир переполнен текстами, изображениями, надписями и различными знаками, которые тесно взаимодействуют между собой. Поэтому вполне закономерно обращение лингвистики к проблеме изучения феномена поликодовых текстов. Впервые креолизованные тексты были рассмотрены и проанализированы в работах по семиотике. В них изображения исследовались как особые знаковые системы, а также были выявлены возможные контексты их применения.

Что касается текстов объявлений о вакансии, то они обладают характерным сочетанием экстралингвистических (коммуникативная ситуация, функция) и интралингвистических параметров (структурные, лексические, грамматические, словообразовательные особенности).

Большинство из них представляют собой семиотически осложнённые или креолизованные тексты с иконическим компонентом. В создании таких текстов большую роль играют вербальные и визуальные составляющие. Не менее важны также невербальные и паралингвистические средства, которые выполняют в тексте аттрактивную, смысловыделительную функции, а также функцию со- 
здания имиджа и подчинены реализации главной задачи текста - найти кандидата на вакантную должность [4, с. 8]. На выбор языковых, невербальных и паралингвистических средств оказывает влияние доминирующая в тексте апеллятивная функция, которая заключается в том, чтобы заинтересовать адресата (соискателя) и сподвигнуть его к выбору вакантной должности. Реализации данной целеустановки служат также частные коммуникативные функции в тексте - информативная, комиссивная и контакто- устанавливающая.

В объявлении о вакансии большое внимание уделяется логике изложения фактов. Композиция данного текста характеризуется строгой структурой. В структуре текста выделяются обязательные (предложение рабочего места, контактная информация) и факультативные (заголовок, презентация работодателя, описание задач, требований к будущему сотруднику, условий работы) композиционные элементы. На специализированных сайтах, например, на таком крупнейшем сайте как monster.de, практически все тексты объявлений о вакансии содержат фотоматериалы, что является невербальным средством привлечения кандидатов на вакансию.

Центральное место в композиционной структуре текста занимают наименования лиц по профессии в заголовке объявления. Обычно они набраны крупным шрифтом и выделены пробелами. Они аппелируют к адресату сообщения и сигнализируют главную тему в сообщении.

Наименования лиц по профессии представляют собой достаточно обширную группу наименований в немецком языке. Эта лексическая группа постоянно изменяется под влиянием процессов, происходящих в современном обществе.

В наше время, практически во все сферы, в том числе и в трудовую деятельность, проникли англицизмы. Считается, что соискатели должны владеть английским языком в совершенстве. Отличное владение английским отмечается в блоке требований к соискателю. Но и само наименование профессии, полностью или частично, представлено английским эквивалентом. На сайте monster.de, наименования лиц по профессии на английском языке, прописанные в заголовках, составляют половину всех размещенных наименований. В некоторых профессиональных сферах, таких как IT или маркетинг, доля английских наименований лиц по профессии составляет 80-90\%.:

- Junior Business Consultant

- PHP Web Developer

- Software Developer/ C\#

-Internship Influencer Marketing

- Big Data Scientist [8].

Интересно отметить тот факт, что, не смотря на такое огромное количество заголовков с английскими наименованиями, сам текст вакансии дается на немецком языке.

Аналогичные тексты вакансий с английскими наименованиями лиц по профессии можно увидеть как в печатной периодике, например, в еженедельной газете Frankfurter Allgemeine, так и на соответствующих сайтах (примеры 1,2).

(1) Unser Auftraggeber ist ein weltweit agierender, nicht börsenkotierter Technologiekonzern auf der Achse Zürich - St. Gallen. Der Konzern ist stetig auf Erfolgs- und Wachstumskurs. Wir sind beauftragt, Sie für die neu geschaffene Funktion des

\section{Team Leader Corporate Content (w/m)}

anzusprechen. Sie führen ein interdisziplinäres Team von Fachspezialisten, mit welchem Sie die operative interne wie externe Kommunikation des Konzerns erledigen, beispielweise Pressemitteilungen, Geschäftsberichte, Kundenzeitschriften etc. Dabei pflegen Sie persönlich den Kontakt zu den Ansprechpartnern und Interessengruppen. Bei Ihrer Tätigkeit setzen Sie alle gängigen Kommunikationswege und Mittel. Sie rapportieren direkt an den Head of Corporate Communication, den Sie auch in allen administrativen Aspekten wie z.B. der Budgetführung unterstützen.

Diese Aufgabe erfordert ein Universitätsstudium z.B. in Germanistik, Geschichte o.a. Eine Weiterbildung beispielweise in Kommunikationswissenschaft ist perfekt. In Deutsch und Englisch drücken Sie sich schriftlich und mündlich souverän aus.

Wir freuen uns auf ihre Bewerbungsunterlagen an:

bewerben@matthias-doel.ch [9]

(2) An der Technischen Universität Hamburg ist im Servicebereich Präsidialbereich Marketing, Presse- und Öffentlichkeitsarbeit, schnellstmöglich folgende - auf 3 Jahre befristete - Stelle zu besetzen 


\section{Projektmanagerin bzw. Projektmanager Social Media}

Teilzeit $50 \%$

Entgeltgruppe $13 \mathrm{TV}-\mathrm{L}$

Kenn-Nr.: SH-17-87

Die Technische Universität Hamburg (TUHH) ist eine international aufgestellte Hochschule mit einer exzellenten Lehre, Forschung und Weiterbildung und bietet ingenieurwissenschaftliche Bachelor- und Masterstudiengänge in allen Fachrichtungen für derzeit über 7.000 Studierende. Sie ist eine wettbewerbsorientierte, unternehmerisch handelnde Universität mit hohem Leistungs- und Qualitätsanspruch. Die TUHH leistet einen Beitrag zur Entwicklung der technisch-wissenschaftlichen Kompetenz der Gesellschaft, indem sie in ihren Forschungsfeldern nationale und internationale Exzellenz anstrebt und den ingenieurwissenschaftlichen Nachwuchs mit modernen Lehr- und Lernmethoden ausbildet.

Wir begrüßen ausdrücklich die Bewerbungen von Menschen mit Migrationshintergrund.

Schwerbehinderte und ihnen gleichgestellte behinderte Menschen haben Vorrang vor gesetzlich nicht bevorrechtigten Bewerberinnen und Bewerbern gleicher Eignung, Befähigung und fachlicher Leistung.

Aufgabenfeld:

Entwicklung und Evaluation neuer Social-Media-Konzepte am Beispiel besonderer Anforderungsprofile im Rahmen des Wachstumsprozesses der TUHH [8].

Приведенные выше тексты объявлений о вакансиях относятся к группе так называемых дикодовых текстов [2], представляющих собой частный случай поликодовых текстов. Речь идет о текстах, в которых используются знаки, принадлежащие только двум семиотическим системам, в данном случае системам немецкого и английского языков. Семиотические системы данных языков могут рассматриваться как основные вербальные составляющие текста объявления о вакансии, соединяющиеся в единое целое общей целеустановкой, характерной для данного типа текста.

Согласно классификации, предложенной Е.Е. Анисимовой [1, с. 15], объявления о вакансии принадлежат группе текстов с умеренной креолизацией, для которых характерно доминирование одной семиотической системы и вспомогательная роль другой. Система английского языка, которой отводится в данных объявлениях второстепенная роль, представлена в анализируемых примерах именными фразами (Team Leader Corporate Content, Projektmanagerin bzw. Projektmanager Social Me$\mathrm{dia}$ ), обозначающими значимые для данной коммуникативной сферы понятия, и синтаксическими моделями (Head of Corporate Communication), характерными для англоязычной речевой практики.

Особый характер связей между элементами английского и немецкого языков, образующими синтаксическое, семантическое и коммуникативное единство в пространстве текстов объявлений о вакансиях, обусловлено реализацией принципа синсемантии и автосемантии, т.е. способностью языковых единиц выражать значение как в сочетании с другими единицами контекста, так и вне зависимости от них [5], Англоязычные включения в текстах немецких объявлений о вакансии представляют собой автосемантичные, т.е. обладающие относительной независимостью по отношению к содержанию всего текста, отрезки. Относительная независимость содержания данных текстовых фрагментов по отношению к общему семантическому пространству текста обусловлена, в первую очередь, тем фактом, что именно в них находит свою объективацию этноспецифическая информация, относящаяся к англоязычной картине мира.

Интегрируясь в семантическое пространство текстов объявлений о вакансии, данные смысловые единицы воспринимаются интерпретатором как некий «внешний» элемент, требующий определенных усилий по расшифровке заложенных автором текста смыслов. Интерпретационная активность адресата предполагает обращение к фрагментам англоязычной картины мира, присутствующим в той или иной степени в сознании любого носителя немецкого языка как следствие процессов глобализации и интеграции экономики Германии в мировую экономику, ориентированную на использование англоязычной терминологической и профессиональной лексики. Так, использование англоязычного словосочетания Corporate Content актуализирует в сознании интерпретатора комплекс представлений о внутреннем устройстве современной корпорации с ее офисной и финансовой документацией, медиаинформацией, виртуальными чатами и форумами, в которых сотрудники корпорации обмениваются информацией, различными базами данных и т.п. Используемая в ближайшем окружении словосочетания Corporate Content фраза Team Leader также соотносится с характерной для англоязычной речевой практикой реалией. Речь идет о специалисте некоторого профиля, имеющим функции менеджера, но по сути своей не являющимся руководителем группы. Анализ совокупного значения дан- 
ных англоязычных единиц приводит к тому, что в сознании интерпретатора формируется образ, отвечающий ожиданиям автора текста объявления о вакансии. Это разработчик программного обеспечения, позволяющего управлять всем объемом корпоративной информации, который будет лидировать в команде IT-персонала компании, являясь лучшим программистом, обладая наибольшей ответственностью и определенными лидерскими качествами.

Дальнейшее направление интерпретирующей деятельности адресата текста объявления о вакансии определяется такими иноязычными включениями, как Head of Corporate Communication и Social-Media-Konzepte. Данные языковые единицы объективируют в приведенных выше текстах объявлений о вакансии такие важные понятия англоязычной картины мира, как Content management system и Enterprise content management, которые являются компонентами более сложного понятия Corporative management, аккумулирующего знания об устройстве и функционировании современной корпорации в англоязычном деловом мире.

Содержание понятия Content management system, на которое указывает обозначение SocialMedia-Konzepte, может быть представлено как система управления корпоративным сайтом (порталом), позволяющая поддерживать его функционирование посредством редактирования содержания, публикации новостей, модерирования дискуссий и т.п. В то время как содержание понятия Enterprise content management, объективируемое лексической единицей Head of Corporate Communication, несколько шире и распространяется на целый комплекс приложений, предназначенных для управления не только корпоративным контентом, но и бизнесс-процессами как таковыми, т.е. включает в себя всю систему документооборота корпорации.

Очевидно, что адекватная интерпретация заложенных автором текста объявления о вакансии смыслов становится возможной при условии владения адресатом специальными знаниями об устройстве корпорации, которые кодируются в современной коммуникативной практике преимущественно средствами английского языка. Таким образом, упоминавшаяся выше текстовая категория автосемантичности имеет когнитивное основание, т.к. автономность приведенных в данной статье текстов обусловлена в известной степени их соотнесенностью с фрагментами англоязычной картины мира, являющейся внешней по отношению к базовой картине мира как автора, так и адресата текста объявления о вакансии. Как следствие, в представленных выше текстах вакансий наименование лица дается на английском языке, а затем следует детальное пояснение вакансии на немецком языке.

Представляется важным отметить, что вопрос о соотношении английской и немецкой языковых картин мира в сознании носителя немецкой культуры остается дискуссионным, свидетельством чему является возрастающее число опубликованных в немецкоязычных источниках объявлений, которые приводятся полностью на английском языке (см. пример).

Research Scientist (Postdoc) ( $\mathrm{m} / \mathrm{f} / \mathrm{d})$ - in Additive Manufacturing

code no. 2019/B 2

The place of employment is Teltow (near Berlin).

The Institute of Biomaterial Science in Teltow of the Helmholtz-Zentrum Geesthacht and Berlin Brandenburg Centre for Regenerative Therapies (BCRT) invite applications for a Postdoc (m/f/d) in Additive Manufacturing with a focus on design, construction and operation of additive manufacturing machines for processing of stimuli-sensitive multifunctional polymeric materials in the context of an EU funded project (https://growbot.eu). This is initially a 2-years fixed term contract.

Within the EU funded project, aiming at the development of plant-inspired growing soft robots, you are responsible for the design, construction and operation of an additive manufacturing machine for processing of stimuli-sensitive multifunctional polymeric materials (i.e. shape-memory polymers). Besides the controlled shaping of the material this machine should in addition allow the chemical modification of the polymeric material e.g. by UV curing. Active participation in the publication of the results, preparation of patents, and in attracting additional funding [8].

Увеличение числа подобных объявлений свидетельствует о значительных изменениях на всех уровнях коммуникативной практики. Изменения на семиотическом уровне обусловлены тем, что знаки английского языка в большинстве случаев имеют меньшую длину, чем их немецкоязычные аналоги, а следовательно, позволяют сэкономить объем рекламного сообщения. На когнитивном уровне можно говорить о вербализации концептов, сформировавшихся в контексте англоязычной лингвокультуры и зачастую еще не нашедших свою объективацию в системе немецкого языка. И, наконец, на прагматическом уровне использование единиц английского языка объясняют глобализацией биз- 
неса. В конце 2009 г. число сотрудников в зарубежных филиалах впервые превысило численность персонала в Германии. Это вынудило организации реагировать на происходящие изменения и ввести единый стандарт обозначения вакансий по всему миру. А раз международный, значит - англоязычный [10].

Благодаря единой системе, зарубежный сотрудник концерна может легко найти в немецкой штаб-квартире коллегу, который отвечает за интересующий его вопрос. Надо отметить что, несмотря на то, что объявления о вакансиях сегодня публикуются на английском языке, далеко не каждый сотрудник владеет им в совершенстве.

Переход с немецкого на английский язык - это еще и инструмент для создания имиджа. Английский ассоциируется с самыми современными веяниями - открытость миру, глобализация. Таким образом, употребляя английские выражения, работодатель может любую позицию заставить звучать престижнее.

\section{СПИСОК ИСТОЧНИКОВ И ЛИТЕРАТУРЫ}

1. Анисимова E. E. Лингвистика текста и межкультурная коммуникация (на материале креолизованных текстов). Москва: Академия, 2003. 128 с.

2. Большакова Л, с. О содержании понятия «поликодовый текст»// Вестник Самарского государственного университета, 2008; №4(63), с. 19-24.

3. Большиянова Л. М. Внешняя организация газетного текста поликодового характера. Типы коммуникации и содержательный аспект языка. Москва: Издательство института языкознания АН СССР, 1987, с. 50-56.

4. Веревкина Ю. О. Немецкие рекламные поликодовые тексты: герменевтический подход. Автореферат. диссертации ... кандидата филологических наук. Самара, 2010. 21 с.

5. Гальперин И. Р. Текст как объект лингвистического исследования. Москва: КомКнига, 2006.

6. Ейгер Г. В. К построению типологии текстов // Лингвистика текста: материалы научной конференции при МГПИИЯ им. М.Тореза. Москва, 1974; Ч.1, с. 103-109.

7. Сонин А. Г. Экспериментальное исследование поликодовых текстов: основные направления // Вопросы языкознания, 2005; №6, с. 115-123.

8. Электронная база вакансий и резюме // URL: https://www.monster.de

9. Frankfurter Allgemeine, 2016: № 3-16.

10. Englishman in Berlin: как читать англо-немецкие объявления о вакансиях // URL: http://www.dw.com/ru/englishman-in-berlin/a-14765385

Кожанова Наталья Викторовна, кандидат филологических наук, доцент, кафедра иностранных языков, ФГБОУ ВО Алтайский государственный педагогический университет, 656031, Россия, г. Барнаул, ул. Молодежная, 55.

E-mail: dsf46k@yandex.ru

\section{N.V. Kozhanova}

\section{CONTEMPORARY GERMAN VACANCY ADVERTISEMENTS AS A POLYCODE TEXT} DOI: $10.35634 / 2412-9534-2020-30-2-258-263$

The article considers the peculiarities of the modern German vacancy advertisement in the context of opposition of monocode and polycode texts. The author pays special attention to the fact of belonging of such texts to two semiotic systems (the German and the English language) that may be viewed as the basic verbal constituents of the vacancy advertisement joined in a whole by the common objective typical of this type of texts. The author analyzes English inclusions in German vacancy advertisement texts that reflect ethnical specific information referring to English picture of the world. The article points out the issue of correlation between English and German language pictures of 
the world remains debatable The results of the analysis allows to make the conclusion that the increasing number of such vacancy advertisements is an evidence of significant changes characteristic of all levels of communicative practice.

Key words: professional denominations, polycode text, creolized text, dicode text, image creating function.

\section{REFERENCES}

1. Anisimova E. E. Lingvistika teksta i mezhkul'turnaya kommunikaciya (na materiale kreolizovannyh tekstov) [Text linguistics and intercultural communication (on the material of creolized texts)]. Moskva: Akademiya, 2003. $128 \mathrm{~s}$. (In Russian).

2. Bol'shakova L. S. O soderzhanii ponyatiya "polikodovyj tekst" [About the content of the concept "polycode text"] // Vestnik Samarskogo gosudarstvennogo universiteta [Bulletin of Samara state University], 2008; №4(63). S. 19-24. (In Russian).

3. Bol'shiyanova L. M. Vneshnyaya organizaciya gazetnogo teksta polikodovogo haraktera. Tipy kommunikacii i soderzhatel'nyj aspekt yazyka [External organization of a newspaper text of a polycode character. Types of communication and content aspect of the language]. Moskva: Izdatel'stvo instituta yazykoznaniya AN SSSR, 1987. S. 5056. (In Russian).

4. Verevkina YU. $O$. Nemeckie reklamnye polikodovye teksty: germenevticheskij podhod. Avtoreferat. dissertacii ... kandidata filologicheskih nauk [German advertising polycode texts: a hermeneutical approach. Autoabstract. theses ... candidate of philology]. Samara, 2010. 21 s. (In Russian).

5. Gal'perin I. R. Tekst kak ob"ekt lingvisticheskogo issledovaniya [Text as an object of linguistic research]. Moskva: KomKniga, 2006. (In Russian).

6. Ejger G. V. K postroeniyu tipologii tekstov [To build a typology of texts] // Lingvistika teksta: materialy nauchnoj konferencii pri MGPIIYA im. M.Toreza [Text linguistics: proceedings of the scientific conference at the Moscow state University. M. Toreza]. Moskva, 1974; CH.1. S. 103-109. (In Russian).

7. Sonin A. G. Eksperimental'noe issledovanie polikodovyh tekstov: osnovnye napravleniya [Experimental research of polycode texts: main directions] // Voprosy yazykoznaniya [Questions of linguistics], 2005; №6. S. 115-123. (In Russian).

8. Elektronnaya baza vakansij i rezyume [Electronic database of vacancies and resumes] // URL: https://www.monster.de (In Russian).

9. Frankfurter Allgemeine, 2016: № 3-16. (In English).

10. Englishman in Berlin: kak chitat' anglo-nemeckie ob"yavleniya o vakansiyah // URL: http://www.dw.com/ru/englishman-in-berlin/a-14765385(In English).

Received: 20.11.2019.

Kozhanova N.V.,

kandidate of Science (Philology), Associate Professor,

foreign languages Department,

Altai State Pedagogical University,

656031 Russia, Barnaul, Molodezhnaya street, 55.

E-mail: dsf46k@yandex.ru 